\title{
Olhares teóricos para a construção de identidades de professores e de alunos por um viés sistêmico-funcional
}

\author{
Adriana Rodrigues de Abreu \\ Pontifícia Universidade Católica do Rio de Janeiro - PUC-Rio/CNPq \\ Adriana Nogueira Accioly Nóbrega \\ Pontifícia Universidade Católica do Rio de Janeiro - PUC-Rio
}

\begin{abstract}
Resumo
Este ensaio tem por objetivo apresentar olhares teóricos como forma de contribuir para reflexões acerca de ambientes pedagógicos, principalmente no que tange à construção de identidades de professores e alunos. Construtos de três pressupostos teóricos são postos em interface: teorias de identidade de viés socioconstrucionista, a Linguística Sistêmico-Funcional e o Sistema de Avaliatividade. A reflexão proposta configura-se no desejo de compartilhar entendimentos sobre questões que envolvem os diferentes ambientes pedagógicos, privilegiando-se uma visão holística das ações observadas. Com isso, esperamos olhar para o espaço escolar em seu fazer natural, mediado por relações entre interlocutores reais, que se posicionam a partir de suas próprias experiências e de outros discursos que os constroem enquanto seres unos e de múltiplas identidades. Palavras-chave: prática pedagógica reflexiva; construção de identidades, linguística sistêmico-funcional; sistema de avaliatividade.
\end{abstract}

\begin{abstract}
This essay aims to present theoretical perspectives as a way to contribute to reflections about pedagogical settings, mainly taking into consideration construction of the identities of teachers and students. Constructs of three theoretical perspectives are interfaced: socioconstrucionist theories of identity, Systemic-Functional Linguistics and Appraisal System. The proposed reflection is based on our desire to share understandings on issues involving different pedagogical environments, giving priority to a holistic view of the observed actions. In this way, we hope to look at the school in its natural doing, mediated by relationships between real interlocutors, who position themselves from their own experiences and from other discourses that construct them as beings with multiple identities.
\end{abstract}

Keywords: pedagogical practice, socioconstruction of identity; systemicfunctional linguistics, appraisal system.

\section{CONSIDERAÇÕES INICIAIS}

Estudar o discurso no contexto educacional é um elemento fundamental para que possamos compreender as relações interpessoais que se estabelecem nesse ambiente 
institucional. Por isso, é essencial refletirmos sobre as diferentes práticas discursivas nas quais professores e alunos estão envolvidos para que, como educadores e pesquisadores, possamos contribuir para tais práticas ao investigarmos o discurso sob uma ótica reflexiva.

Com base nesse olhar reflexivo e em nossas experiências pedagógicas (como professora de escolas públicas de redes municipais e como professora universitária) é que propomos este ensaio de cunho sócio-reflexivo.

A reflexão que trazemos neste momento configura-se em nosso desejo de compartilhar nossos entendimentos sobre questões que envolvem os diferentes ambientes pedagógicos em que atuamos. Além disso, desejamos propor olhares teóricos que nos apoiem em nossas práticas reflexivas e acreditamos que tal reflexão se torne relevante exatamente por poder ser tida como uma importante contribuição para o ensino, para as nossas práticas pedagógicas e as de nossos colegas, bem como para as comunidades em que atuamos como professoras.

A fim de discutirmos sobre o contexto pedagógico, e de como podemos pensá-lo teoricamente para entendermos nossas práticas dentro e fora da sala de aula, partimos do pressuposto teórico de que os enunciados criados em nossas trocas interacionais formam as identidades de professores e alunos a cada evento comunicativo, já que nos alinhamos com as teorias socioconstrucionistas e com a sua visão de que o processo identitário é um fenômeno discursivo, construído e negociado na interação (BHABHA, 1994; BUCHOLTZ e HALL, 2005; MOITA LOPES, 2002, 2003).

Levando em consideração que a identidade está em constante mutação, não sendo considerada um produto acabado (BHABHA, 1994), é importante observar os discursos que circulam no ambiente investigado, já que as identidades sociais são definidas "nos e pelos discursos que a envolvem ou nos quais a pessoa circula" (MOITA LOPES, 2003, p. 20). Dessa forma, temos consciência de que tais discursos são construídos durante as interações sociais e são formados por elementos avaliativos, inerentes à linguagem, sendo, por isso, fundamental adotarmos os princípios teóricos da Linguística Sistêmico-Funcional (HALLIDAY, 1978, 1994; HALLIDAY e HASAN, 1989) e do Sistema de Avaliatividade (MARTIN e WHITE, 2005). Tais teorias sociossemióticas são instrumentos teóricos que possibilitarão ações teórico-reflexivas voltadas aos contextos de atuação e aos participantes que os constroem.

Adotamos nesta proposta a perspectiva de linguagem da Linguística SistêmicoFuncional por compartilharmos a visão funcionalista de linguagem proposta por essa abordagem. De acordo com Halliday (1994), a linguagem é um sistema de construção de significados, sendo um instrumento de interação social, cujo objetivo primeiro é estabelecer a 
comunicação entre interlocutores reais. A Avaliatividade, por sua vez, contempla a avaliação e fornece elementos linguísticos para uma análise sobre o modo pelo qual os sujeitos, com base em uma gama de opções do sistema linguístico, posicionam-se no discurso no momento em que expressam suas opiniões, sentimentos e emitem seus comentários acerca de suas percepções de mundo. As teorias sociossemióticas da linguagem, então, são significativas para o trabalho aqui proposto, uma vez que constituem um aporte teórico importante para contribuir para a investigação das identidades que emergem nos discursos.

Inserida na área de Linguística Aplicada, a proposta reflexiva que trazemos para este ensaio, ao entrelaçar os pressupostos teóricos de identidade (BHABHA, 1994; BUCHOLTZ e HALL, 2005; MOITA LOPES, 2002, 2003) à perspectiva da Linguística Sistêmico-Funcional e ao Sistema de Avaliatividade (MARTIN, 2000; MARTIN e WHITE, 2005), pretende fundamentar uma investigação reflexiva que contemple como os sujeitos são construídos na interação e como os elementos avaliativos são importantes para a formação das identidades dos participantes ali envolvidos. Acreditamos que, com base nesses olhares teóricos, é possível examinarmos a visão de alunos e de professores sobre as suas experiências pedagógicas, dentro e fora do ambiente escolar em que estão inseridos, assim como observarmos como os elementos avaliativos constroem as identidades dos professores e dos alunos no ambiente em que atuam.

Cabe destacar que privilegiamos uma visão social da sala de aula, tratando os participantes que ali habitam como seres construídos sociohistoricamente; isto é, em suas relações sociais eles se (re)constroem na medida em que interagem com o outro. Neste ambiente social, tanto os alunos como os professores geram conhecimento e compartilham as suas experiências. Uma reflexão como a que ora apresentamos, então, será uma oportunidade para a troca de conhecimentos e de vivências; certamente, para que uma prática reflexiva como a que sugerimos seja coerente, é preciso considerar o contexto social em que os participantes estão inseridos, suas histórias de vida, suas experiências dentro e, se possível, fora da sala de aula. Além disso, é essencial conduzirmos nossos olhares investigativos por meio da análise das práticas discursivas pedagógicas, isto é, da linguagem presente em nossos ambientes de investigação, que são tidas como constitutivas desse mesmo contexto educacional e, portanto, são concebidas como um fenômeno social, construído em situações reais de interlocução. 


\section{OLHARES TEÓRICOS E SUAS INTERFACES ANALÍTICAS}

Como dito anteriormente, os olhares teóricos que embasam nossa proposta encontramse em interface: a concepção de identidade, de acordo com teorias socioconstrucionistas (BUCHOLTZ e HALL, 2003, 2005; MOITA LOPES, 2001, 2002, 2003) alinhavam-se aos princípios teóricos da Linguística Sistêmico-Funcional (HALLIDAY, 1994; HALLIDAY e HASAN, 1989), especialmente no que compreende a visão sociossemiótica de linguagem, e aos pressupostos teóricos da Avaliatividade (MARTIN e WHITE, 2005), sistema da Linguística Sistêmico-Funcional, mais especificamente, do estrato semântico discursivo interpessoal.

Por certo, faz-se necessário recorrermos à dinâmica entre linguagem e sociedade para compreendermos o processo de construção identitária, uma vez que as identidades têm as suas origens em processos históricos e sociais. As práticas discursivas, o mundo social e as identidades encontram-se imbricadas, entrelaças a partir do uso vivo da linguagem. Bastos e Oliveira (2006) definem a construção identitária como um ato performativo, evidenciado no período em que as pessoas expõem quem elas são nos diversos momentos de interações sociais. Tal ponto de vista nos remete ao aspecto interacional e discursivo onde as identidades emergem.

Para Moita Lopes (2003), a identidade é um construto de natureza social, construída em práticas discursivas, não dizendo respeito a uma visão de identidade como parte da natureza de uma pessoa. Ao contrário, o autor afirma que a identidade é construída no discurso, sendo o indivíduo membro de muitos discursos, que representam cada uma das suas múltiplas identidades. Desse modo, as identidades não estão prontas e fixas, elas são construídas e formadas nas práticas de uso da linguagem. Segundo Bucholtz e Hall (2003, 2005), as identidades são moldadas a cada momento durante a interação e emergem no contexto do discurso.

Como a identidade é um produto não acabado (BHABHA, 1994), podemos dizer que o ser humano está em permanente estado de fluidez. Por esse viés, Hall (1996, apud MOITA LOPES, 2001, p. 61) apreende que a identidade é um processo de transformação, que está relacionada ao "tornar-se" e não ao "ser". Portanto, a construção identitária é (re)elaborada no discurso, no momento em que nos engajamos em práticas discursivas. Tendo em vista que as identidades são construídas discursivamente, elas ocorrem durante a interação com o outro. Por isso, é válido enfatizarmos que a noção de identidade está atrelada à relação de um sujeito com o outro, ou, em outras palavras, podemos dizer que, no caso deste estudo, as identidades 
dos professores e dos alunos podem transformar-se em seu discurso como participantes inseridos em um contexto sociocultural, histórico e político, que os tornam únicos e diferentes de qualquer outro.

Pelo caráter discursivo das teorias de identidade, acreditamos ser importante trazermos uma visão que contemple os aspectos semânticos e funcionais da linguagem, assim como os elementos avaliativos que compõem os enunciados dos participantes deste estudo, já que os sujeitos são construídos na e pela linguagem. Centramos nosso olhar, portanto, na Linguística Sistêmico-Funcional (LSF), desenvolvida por Michael Halliday (1978, 1994), e que é uma teoria que ressalta a importância do aspecto social na construção do discurso, voltando-se para as práticas sociais de uso da linguagem. Podemos, assim, descrever a LSF "como uma abordagem interpretativa e descritiva que possibilita entendermos a linguagem como um recurso estratégico e criador de significados” (Eggins, 2004, p. 2).

Para Halliday, são três os significados da linguagem: ideacional, interpessoal e textual. Esses significados são inseparáveis de três elementos do contexto, que influenciam nossas escolhas. A noção de contexto é fundamental para a Linguística Sistêmico-Funcional, pois todo texto ocorre em dois contextos: o de cultura e o de situação. O contexto de cultura é amplo e envolve todos os possíveis sentidos de uma dada cultura e o de situação, por outro lado, é particular, pois abrange a realização da linguagem em determinado contexto. Halliday (1994) propõe que o contexto situacional se caracteriza a partir de três variáveis: campo (que corresponde à atividade social desenvolvida e à natureza da ação social em questão); relações (que diz respeito a quem está participando de uma dada situação, bem como à natureza, status e papéis desses participantes) e modo (que está relacionado ao uso do idioma, bem como ao canal utilizado).

Segundo Halliday e Hasan (1989), a essência da abordagem funcional é a sua multifuncionalidade, ou seja, a possibilidade de tratar todo enunciado a partir de diferentes perspectivas. Com base em uma visão tríade do sistema linguístico, as dimensões contextual, semântica e lexicogramatical estão inter-relacionadas, não sendo possível entender a linguagem de forma isolada de tais dimensões. Por esse motivo, a esfera social é muito relevante para a análise da linguagem, uma vez que a mesma só pode ser investigada a partir do uso que fazemos dela, conforme estamos observando desde o início deste ensaio e das teorias aqui escolhidas para nortear esta proposta de estudo.

Uma das formas de investigarmos a prática discursiva e os sentidos que nela se criam é com base no Sistema de Avaliatividade, sistema da LSF, mais especificamente do significado interpessoal, no nível da semântica do discurso. O significado interpessoal está voltado para 
os participantes da interação, os papéis sociais que os mesmos desempenham e as relações que são estabelecidas na interação. Por lidar com as relações interpessoais, por meio da análise da atitude e do posicionamento do falante, o Sistema de Avaliatividade insere-se na metafunção interpessoal a fim de avaliar as evidências discursivas presentes nas interações.

Logo, o Sistema de Avaliatividade lida com os significados que são construídos durante as interações sociais, em contextos específicos de interação. Todos os significados avaliativos são interpretados de acordo com os aspectos contextuais e socioculturais. De acordo com Martin e White (2005), um item lexical normalmente sofre alterações quanto ao seu valor, pois depende do contexto em que ele foi produzido.

O Sistema de Avaliatividade é composto por três sistemas/domínios que se interrelacionam: Atitude, Engajamento e Gradação. O domínio da Atitude está preocupado com nossas emoções; o Engajamento (posicionamento) trata da interação das vozes que envolvem as opiniões do discurso; e a Gradação lida com a gradação dos fenômenos onde os sentimentos são ampliados e/ou atenuados (MARTIN e WHITE, 2005).

Em suma, a perspectiva socioconstrucionista de identidade constitui um dos pilares propostos para a reflexão docente, por ser uma teoria que concebe a identidade como um fenômeno sociocultural e discursivo. De igual modo, as duas teorias sociossemióticas de linguagem são fundamentais para analisar os discursos construídos nos ambientes onde nos fazemos presentes, fornecendo instrumentos importantes para uma análise linguística, com foco nas marcas discursivas avaliativas.

As teorias selecionadas para fundamentar a reflexão investigativa sugerida neste ensaio, então, constituem um olhar teórico rico, pois tratam a linguagem a partir de sua natureza social, do mesmo modo que consideram o sujeito como um ser construído em suas relações interacionais com o outro. A riqueza presente nos olhares teóricos que buscamos trazer para alicerçar reflexões acerca de nossas práticas pedagógicas pressupõe, ainda, a interpretação dos fatos que circulam em nossas rotinas, uma vez que acreditamos que a interpretação é inerente ao ato de investigar (ERICKSON, 1990). Desse modo, fazemos prevalecer uma visão holística das ações observadas, não se tendo como propósito alcançar generalizações, mas sim o entendimento das singularidades encontradas nos campos pesquisados (LÜDKE e ANDRÉ, 2001). 


\section{CONSIDERAÇÕES REFLEXIVAS FINAIS}

Tomando por base os vieses teóricos descritos, esperamos olhar para o espaço escolar em seu fazer natural, mediado por relações entre interlocutores reais, que se posicionam a partir de suas próprias experiências e de outros discursos que os constroem enquanto seres unos e de múltiplas identidades. Entendemos que analisar os ambientes escolares nos quais estamos inseridos é fundamental para compreendermos nossa prática como participantes ativos desses contextos. Com isso, não temos a pretensão de mudar tais ambientes, mas de propor o debate e a reflexão sobre a sala de aula, local de construção de saberes e de troca de experiências. De igual forma, pensamos em oferecer outras possibilidades para o entendimento das experiências pedagógicas de professores e de alunos.

\section{REFERÊNCIAS BIBLIOGRÁFICAS}

BASTOS, L. C.; OLIVEIRA, M. C. L. Identity and personal/institutional relations: people and tragedy in a health insurance customer service. In: FINA, A. de; SCHIFFRIN, D.;

BAMBERG, M. Discourse and identity. Cambridge: Cambridge University Press, 2006.

BHABHA, H. K. The location of culture. London and New York: Routledge, 1994.

BUCHOLTZ, M.; HALL, K. Language and Identity. In: DURANTI, A. (ed.) A Companion to Linguistic Anthropology. Oxford, Basil Blackwell, 2003.

Identity and Interaction: A Sociocultural Linguistic Approach.

Discourse Studies, v. 7, n. 4-5, p. 585-614, 2005.

EGGINS, S. An Introduction to Systemic Functional Linguistics. London: Continuum, 2004.

ERICKSON, F. Qualitative Methods. In: LINN, R. L.; ERICKSON, F. (eds.) Quantitative Methods, Qualitative Methods. New York, Macmillan, v. 2, p. 75-194, 1990.

HALL, S. A identidade cultural na pós-modernidade. Tradução de Tomaz Tadeu da Silva. Rio de Janeiro: DP\&A Editora, 2005.

HALLIDAY, M. A. K. Language as social semiotic. London: Arnold, 1978.

. An Introduction to Functional Grammar. 2 ed. London: Arnold, 1994.

; HASAN, R. Language, context, and text. Aspects of Language in a social-semiotic Perspective. Oxford: Oxford University Press, 1989.

LÜDKE, M.; ANDRÉ, M. E. Pesquisa em educação: abordagens qualitativas. São Paulo: EPU, 2001. 
MARTIN, J. R. Beyond Exchange: Appraisal Systems in English. In: HUNSTON, S.; THOMPSON, G. (Orgs.) Evaluation in Text: Authorial Stance and the Construction of Discourse. Oxford: OUP, 2000, p. 142-175.

MARTIN, J.; WHITE, P. The Language of Evaluation: Appraisal in English. New York: Palgrave/Macmillan, 2005.

MOITA LOPES, L. P. Práticas narrativas como espaço de construção de identidades sociais: uma abordagem socioconstrucionista. In: RIBEIRO, B. T.; LIMA, C.; DANTAS, M. T. (Orgs.) Narrativa, identidade e clínica. Rio de Janeiro: IPUB, 2001.

. Identidades fragmentadas: a construção discursiva de raças, gênero e sexualidade em sala de aula. Campinas, SP: Mercado de Letras, v. 1, 2002.

. Socioconstrucionismo: discurso e identidades sociais. In: MOITA LOPES, L. P. (Org.) Discurso de identidades. Campinas: Mercado de Letras, 2003.

\section{AS AUTORAS}

Adriana Rodrigues de Abreu - Pontifícia Universidade Católica do Rio de Janeiro.

Doutoranda em Estudos da Linguagem pela Pontifícia Universidade Católica do Rio de Janeiro (PUC-Rio), com bolsa pelo Conselho Nacional de Desenvolvimento Científico e Tecnológico (CNPq). Mestre em Estudos da Linguagem pela PUC-Rio. Graduada em Letras pela Universidade do Estado do Rio de Janeiro/ Faculdade de Formação de Professores (UERJ/FFP). Foi bolsista FAPERJ 10 durante o Mestrado e bolsista de Iniciação Científica (PIBIC/CNPQ), na graduação. Atualmente é professora das Redes Municipais de Ensino do Rio de Janeiro e de Magé. Faz parte do Grupo de Pesquisa Análise sistêmico-funcional e Avaliatividade no Discurso.

E-mail: adrianarodriguess@yahoo.com.br

Adriana Nogueira Accioly Nóbrega - Pontifícia Universidade Católica do Rio de Janeiro.

Doutora e Mestre em Letras pela Pontifícia Universidade Católica do Rio de Janeiro, na área de Estudos da Linguagem. Professora Adjunta do Departamento da Letras da PUC-Rio, atua na linha de pesquisa Discurso, vida social e práticas profissionais do Programa de PósGraduação Estudos da Linguagem. Suas áreas de interesse compreendem Linguística Aplicada, Linguística Sistêmico-Funcional, Análise de Discurso Crítica, Gêneros discursivos e Estudos da narrativa e de identidade. Bolsista do Programa de Incentivo à Produtividade em Ensino e Pesquisa (PUC-Rio).

E-mail: adriananobrega@puc-rio.br 